\title{
ERROR ANALYSIS AND VALIDATION FOR INSAR HEIGHT MEASUREMENT INDUCED BY SLANT RANGE
}

\author{
Xiang Zhang ${ }^{*}$, Tao Li, Wenfeng Fan, Xiaomeng Geng \\ Satellite Surveying and Mapping Application Center, National Administration of Surveying, Mapping and Geo-information, Beijing, \\ China - (zhangx, lit, fanwf, gengxm)@ sasmac.cn
}

Commission III, WG III/3

KEY WORDS: InSAR, DEM, Slant Range Error, Simulation Validation, SRTM, TanDEM-X

\begin{abstract}
:
InSAR technique is an important method for large area DEM extraction. Several factors have significant influence on the accuracy of height measurement. In this research, the effect of slant range measurement for InSAR height measurement was analysis and discussed. Based on the theory of InSAR height measurement, the error propagation model was derived assuming no coupling among different factors, which directly characterise the relationship between slant range error and height measurement error. Then the theoretical-based analysis in combination with TanDEM-X parameters was implemented to quantitatively evaluate the influence of slant range error to height measurement. In addition, the simulation validation of InSAR error model induced by slant range was performed on the basis of SRTM DEM and TanDEM-X parameters. The spatial distribution characteristics and error propagation rule of InSAR height measurement were further discussed and evaluated.
\end{abstract}

\section{INTRODUCTION}

Synthetic aperture radar interferometry (InSAR), which utilizes the phase information of SAR images, is a promising earth observation technique (Massonnet, 1997; Hanssen, 2001). It is particularly useful in cartography (Zebker and Goldstein, 1986; Farr et al., 1999) and deformation monitoring (Zebker et al., 1994; Mohr et al., 1998). Therefore, it has been widely used for city subsidence studies, glacier movement monitoring, landslides and digital elevation model (DEM) generation (Zink et al., 2006; Krieger et al., 2007). DEMs are of fundamental importance for a broad range of commercial and scientific applications. Many geoscience areas, like hydrology, glaciology, forestry, geology, oceanography and land environment, require precise and up-to-date information about the earth's surface and its topography. The Shuttle Radar Topography Mission (SRTM) (Rosen et al., 2000; Werner, 2001; Rabus et al., 2003) had the challenging goal to meet the requirements for a homogeneous and reliable DEM fulfilling the DTED-2 specification. TanDEM-X mission has achieved the global DEM generation following the HRTI-3 standard (Pitz and Miller, 2010; Werninghaus and Buckreuss, 2010). The potential of InSAR technique for global DEM production has been widely demonstrated.

The generation of accurate InSAR-derived DEM requires a precise knowledge of the slant range. Therefore high-precision measurement of slant range is a prerequisite for InSAR system. The essence of the slant range measurement between the radar antenna and target is the measurement of the time interval between the antenna emission and echo pulse. The time delay of the radar system can be measured by the GPS real time clock. However, the emission and receive of the electromagnetic wave are influenced by the radar system and external environment, especially for timing, clock jitter and effects of the troposphere and ionosphere (Meyer et al., 2006). Thus the inevitable time delay error will induce the deviation of the slant range measurement.

Slant range determination is a key technique for interferometric synthetic aperture radar (InSAR) system. In this research, the impacts of slant range error to InSAR height measurement were comprehensively discussed, and simulation validation was implemented to evaluate the spatial distribution characteristics of the height error induced by slant range error. This paper starts with a description of observation geometry for InSAR height measurement. The characteristic of the slant range error is analysed, and the slant range error model is structured on the basis of the first-order derivative model. In combination with the TanDEM-X configuration, the theoretical relationship between slant range error and height measurement error was quantitatively evaluated. Furthermore, based on the SRTM DEM and TanDEM-X parameters the simulation validation of the slant range error model was performed to assess the spatial distribution of height error. In conclusion, according to the slant range error evaluation and validation, high precision InSAR slant range determination should be achieved for InSAR height measurement.

The paper is structured as follows. An overview of the study area and description of the data set are presented in section 2 . The methodology of slant range error analysis and simulation strategy are presented in section 3. The results and discussions in section 4 is divided into two parts associated with 1) theoretical-based point scale quantitative evaluation and 2) spatial simulation validation of the slant range error to height measurement. Finally, the conclusions are presented in section 5.

\section{EXPERIMENTAL AREA AND DATA SET}

The study area located in the southwest of DengFeng, China $\left(112.96^{\circ}-113.08^{\circ} \mathrm{E}, 34.33^{\circ}-34.44^{\circ} \mathrm{N}\right)$, shown as figure 1 . This

*Corresponding author 
area consists primarily of plain. The highest elevation is about $550 \mathrm{~m}$, and the lowest elevation is about $190 \mathrm{~m}$.

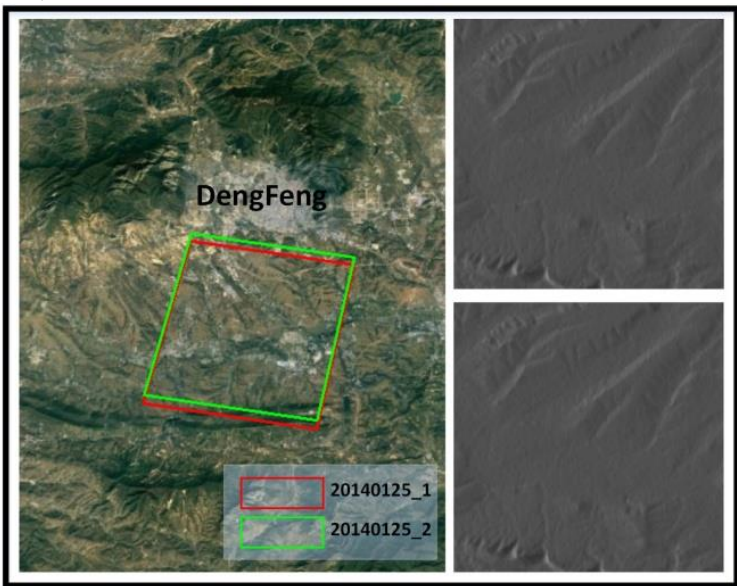

Figure 1. Study area and image range.

The TerraSAR-X/TanDEM-X data was acquired over the study area on 25 January 2014 . The incidence angle is about $46.8^{\circ}$, and the orbit direction of the image is descending. The azimuth and range resolution is approximate $2.1 \mathrm{~m}$ and $1.4 \mathrm{~m}$, respectively. The detailed information of TerraSAR-X/ TanDEM-X data is listed in Table 1. Both of the simulation analysis and validation are implemented on the basis of the TerraSAR-X/TanDEM-X configuration parameters.

\begin{tabular}{ccc}
\hline Parameters & $20140125 \_1$ & $20140125 \_2$ \\
\hline Orbit inclination & $97.4472^{\circ}$ & $97.4472^{\circ}$ \\
Incidence angle & $46.7916^{\circ}$ & $46.7852^{\circ}$ \\
Azimuth resolution & 2.0529 & 2.0529 \\
Range resolution & 1.3641 & 1.3641 \\
Near slant range & 707992.1106 & 707930.7258 \\
Center slant range & 711401.6910 & 711340.3062 \\
Far slant range & 714811.2715 & 714749.8867 \\
PRF & $3.43 \mathrm{KHz}$ \\
Wavelength & $0.03125 \mathrm{~m}$
\end{tabular}

Table 1. Detailed information of TerraSAR-X/TanDEM-X

\section{METHODOLOGY}

\subsection{Slant range error model of InSAR}

The observation geometry of the InSAR measurement is showed as Figure 2. $S_{1}$ and $S_{2}$ is the antenna phase center corresponding to the master and slave image, respectively. The spatial baseline is generated due to the position difference between $S_{1}$ and $S_{2}$, which is denoted as $B$. $\alpha$ represents the angle between the baseline and horizontal direction. $\theta$ is the radar incidence angle. $B_{\perp}$ denotes the perpendicular baseline. $r$ and $r+\Delta r$ is the slant range between the master and slave antenna phase center to target point, respectively. $H$ is the satellite altitude, $R_{H}$ and $R_{h}$ is the distance from satellite and ground point to earth center, respectively. $R e$ denotes the earth radius, and $h$ is the height of the ground point.

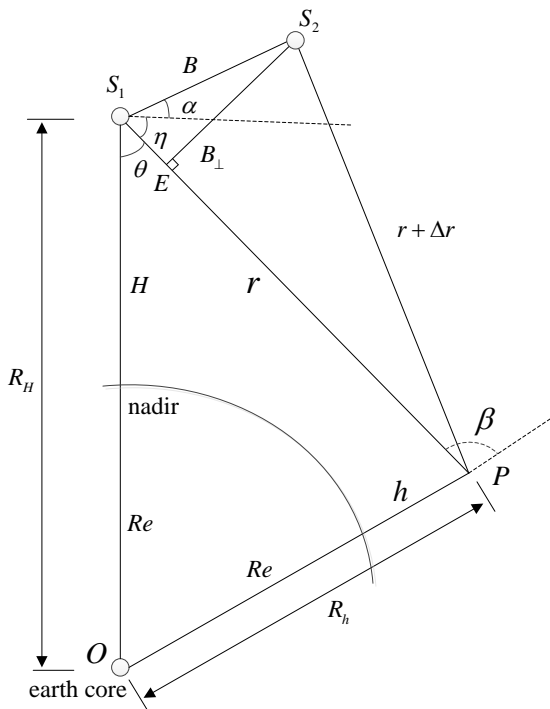

Figure 2. Observation geometry of InSAR

Figure 2 shows the observation geometry of the InSAR measurement. According to the cosine law, the geometry representation can be obtained in the $S_{1} O P$ triangle.

$$
\left(h+R_{e}\right)^{2}=R_{\mathrm{H}}^{2}+r^{2}-2 r R_{H} \cos \theta
$$

Thus, $h$ can be represented as:

$$
h=\sqrt{R_{H}^{2}+r^{2}-2 r R_{H} \cos \theta}-R_{e}
$$

In the $S_{1} P S_{2}$ triangle, the geometry relationship can be derived on the basis of cosine law.

$$
\cos (\eta+\alpha)=\frac{B^{2}+r^{2}-(r+\Delta r)^{2}}{2 B r}
$$

Where

$$
\Delta r=\frac{\lambda}{2 \pi} \varphi
$$

The following representation can be obtained.

$$
\sin (\theta-\alpha)=\frac{B^{2}+r^{2}-\left(r+\frac{\lambda}{2 \pi} \varphi\right)^{2}}{2 B r}
$$

In addition,

$$
\begin{gathered}
\cos \alpha=\frac{\sqrt{\mathrm{B}_{X}^{2}+\mathrm{B}_{Y}^{2}}}{B} \\
\sin \alpha=\frac{B_{\mathrm{Z}}}{B} \\
B=\sqrt{B_{X}^{2}+B_{\mathrm{Y}}^{2}+B_{Z}^{2}} \\
R_{H}=\sqrt{X_{1}^{2}+Y_{1}^{2}+Z_{1}^{2}}
\end{gathered}
$$

Where, $\varphi$ is the unwrapped phase of the ground point $\mathrm{P} .\left[\mathrm{B}_{\mathrm{X}}, \mathrm{B}_{\mathrm{Y}}\right.$, $\left.\mathrm{B}_{\mathrm{Z}}\right]$ denotes three dimensional vector of the baseline. $\left[\mathrm{X}_{1}, \mathrm{Y}_{1}\right.$, 
$\mathrm{Z}_{1}$ ] is the three dimensional coordinate of the antenna phase center of the master image. $r$ is the slant range of the master image. These eight variables constitute the model observations for InSAR height measurement. The slant range is a significant variable for the model solution, thus the influence of the slant range error to height measurement were discussed comprehensively.

Based on the above theoretical derivation of the InSAR height measurement model, the error model of the slant range to height measurement can be derived through the partial derivative processing. Assuming there is no coupling among the satellite orbit, interferometric phase, baseline and slant range, thus the relationship between the slant range error and height measurement can be derived as follows:

$\sigma_{r}^{h}=\frac{1}{R_{e}+h}\left|\left[r-R_{H} \cos \theta-R_{H} \sin \theta \frac{\frac{\lambda}{2 \pi} \varphi-B_{Y} \cos \theta+B_{Z} \sin \theta}{B_{Y} \sin \theta+B_{Z} \cos \theta}\right]\right| \sigma_{r}$

This equation straightforward characterise the error propagation characteristics from the slant range error to height measurement.

\subsection{Simulation strategy}

The simulation validation is the inverse process of the InSAR data processing. The primary process consists of the DEM cropping, intensity simulation, flat phase simulation, topographic phase simulation, as well as SLC structuring.

Before the DEM cropping, the original DEM required to be mapped into the SAR coordinate space. The R-D model was employed to implement this procedure.

$$
\left\{\begin{array}{l}
1=\frac{X_{t}^{2}+Y_{t}^{2}}{\left(R_{e}+H_{t}\right)^{2}}+\frac{Z_{t}^{2}}{R_{p}^{2}} \\
R=\left|R_{s c}-R_{t c}\right| \\
f_{d}=-\frac{2}{\lambda} \frac{\left(R_{s c}-R\right) V_{s c}}{\left|R_{s c}-R_{t c}\right|}
\end{array}\right.
$$

$R$ denotes the slant range, $R_{s c}$ is the satellite position vector $\left(\mathrm{X}_{\mathrm{s}}\right.$, $\left.\mathrm{Y}_{\mathrm{s}}, \mathrm{Z}_{\mathrm{s}}\right), R_{t c}$ is the ground point position vector $\left(\mathrm{X}_{\mathrm{t}}, \mathrm{Y}_{\mathrm{t}}, \mathrm{Z}_{\mathrm{t}}\right), f_{d}$ denotes the Doppler frequency shift, $\lambda$ is the radar wavelength, $V_{s c}$ is the satellite velocity vector $\left(\mathrm{X}_{\mathrm{v}}, \mathrm{Y}_{\mathrm{v}}, \mathrm{Z}_{\mathrm{v}}\right), R_{e}$ is the earth radius, $R_{p}$ is the polar radius, and $H_{t}$ is the height of the target point.

Figure 3 shows the mapped and clipped DEM over the study area.

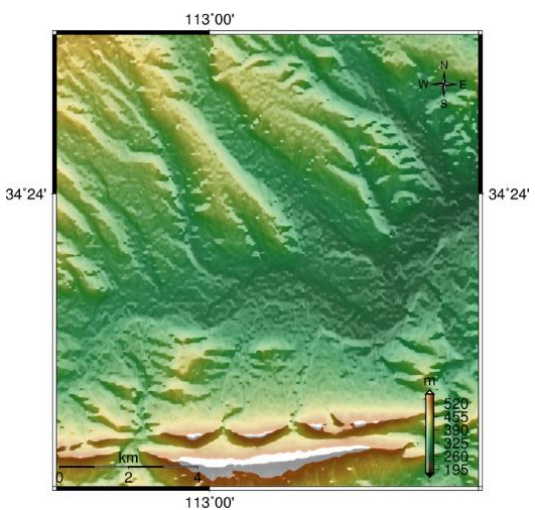

Figure 3. SRTM DEM of the study area
For the intensity simulation, the radar incidence angle, heading angle and some other parameters are required in this procedure. The relationship can be represented as follows:

$$
d_{(x, y)}=\sum_{(X, Y, Z)} I_{0} \frac{R_{\text {near }}^{4}}{R_{(X, Y, Z)}^{4}} \cos \theta_{(X, Y, Z)}
$$

Where, $I_{o}$ is the given microwave radiation intensity of the near range, $R_{\text {near }}$ is the near range delay, and $R_{(X, Y, Z)}$ is the slant range. The simulated intensity image shows as figure 4 . The simulated results represent comparable textural characteristics with the SRTM DEM.
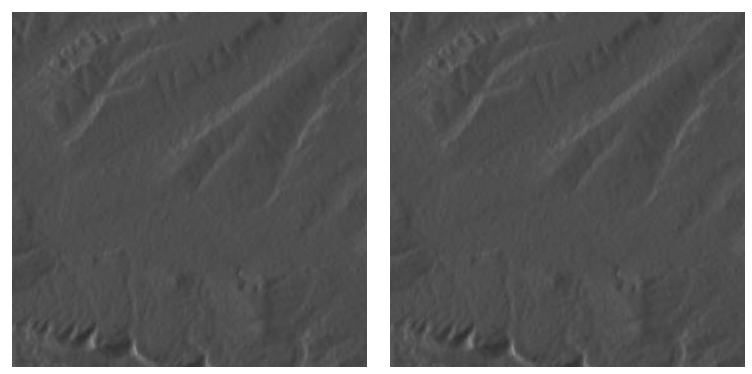

Figure 4. Simulated intensity image (Left: master image, Right: slave image)

Generally, the phase of the master image does not require more treatment, which is given as a constant. Thus, the phase of the slave image can be derived in combination with the flat phase and topographic phase. The flat phase and topographic phase can be expressed as equation (13) and (14), respectively.

$$
\begin{gathered}
\varphi_{f l t}=\varphi_{1}-\varphi_{2}=-\frac{2 \pi}{\lambda} \Delta r \\
\Delta \varphi=\frac{2 \pi B_{\perp} h}{\lambda r \sin \theta}
\end{gathered}
$$

The simulated flat phase and topographic phase show as figure 5 .

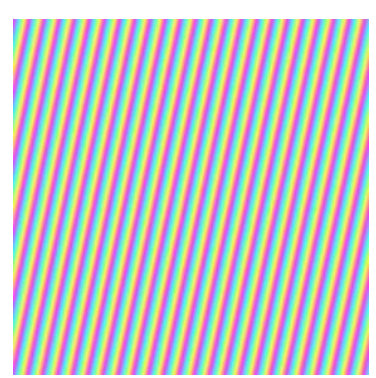

(a) Flat phase

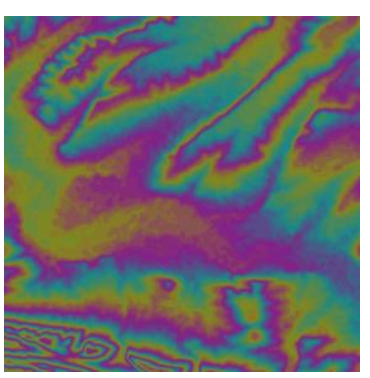

(b) Topographic phase
Figure 5. Simulated results of the flat phase and topographic phase.

When the amplitude $A$ and phase $\varphi$ were simulated, the complex value of the simulated master and slave image can be obtained.

$$
c=a+b i
$$

Where, $a=A \cos \varphi, b=A \sin \varphi$.

According to the above simulation strategy, the simulation validation of the slant range error to InSAR height measurement can be implemented on the basis of the TanDEM-X parameters and SRTM DEM. 


\section{RESULTS AND DISCUSSIONS}

\subsection{Theoretical-based point scale evaluation}

According to the TanDEM-X configuration, the error of slant range varies from $1 \mathrm{~m}$ to $10 \mathrm{~m}$. The influence of the slant range error to height measurement was assessed on the basis of the theoretical error propagation model. Figure 6 shows the relationship between the slant range error and height error.

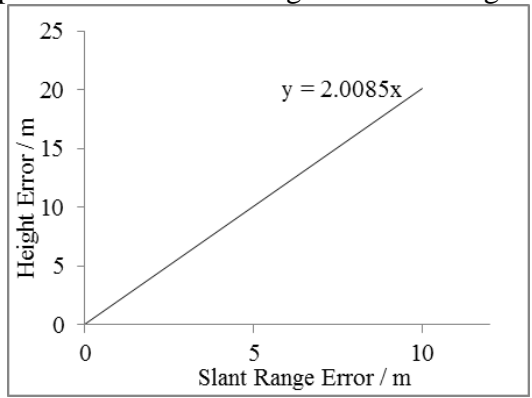

Figure 6. Relationships between the slant range error and height measurement

The simulation results indicate that with the increase of the slant range error the height measurement error linearly raises. Meterlevel error of the slant range can result in meter-level error for InSAR height measurement. Therefore, the accurate determination of the slant range is crucial for InSAR height measurement.

Given the slant range error $\Delta \mathrm{r}=0.5 \mathrm{~m}$ and $\Delta \mathrm{r}=3 \mathrm{~m}$ respectively, the influence of the incidence angle to height measurement was further discussed. The incidence angle varies from $20^{\circ}$ to $60^{\circ}$. Figure 7 shows the relationships between incidence angle and height error.

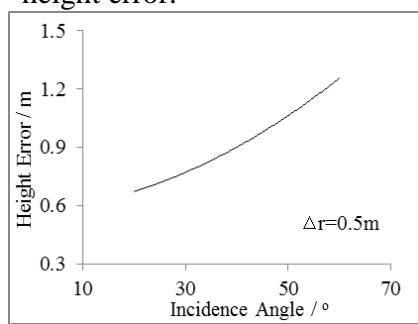

(a) $\Delta \mathrm{r}=0.5 \mathrm{~m}$

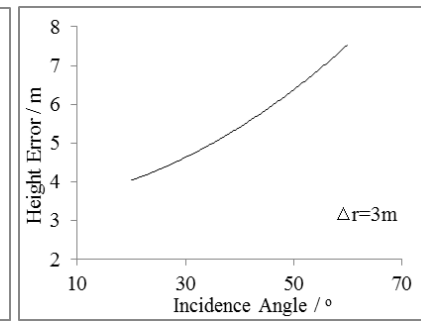

(b) $\Delta \mathrm{r}=3 \mathrm{~m}$
Figure 7. The relationships between the incidence angle and height error

The results show that for the given slant rang error the height measurement error rises with the incidence angle increase. For the specific slant range error, the height measurement error changes obviously for different incidence angle. Therefore, the appropriate selection of the incidence angle is favorable for InSAR height measurement.

\subsection{Spatial simulation validation of the slant range error to height measurement}

Based on the theoretical analysis of the slant range error to height measurement, the spatial simulation validation of slant range error to height measurement was implemented in combination with the TanDEM-X configuration and SRTM DEM. The spatial distribution characteristics of the height error induced by slant range error was further quantitatively evaluated and discussed.
Given the slant range error $\Delta \mathrm{r}=1 \mathrm{~m}, \Delta \mathrm{r}=2 \mathrm{~m}, \Delta \mathrm{r}=2.5 \mathrm{~m}, \Delta \mathrm{r}=3$ $\mathrm{m}, \Delta \mathrm{r}=3.5 \mathrm{~m}, \Delta \mathrm{r}=4 \mathrm{~m}, \Delta \mathrm{r}=4.5 \mathrm{~m}$ and $\Delta \mathrm{r}=5 \mathrm{~m}$ respectively, the influence of different slant range error to height measurement was quantitatively assessed. Based on the SRTM DEM, the height error distribution induced by the different slant range error was analysised and evaluated. Figure 8 shows the height error distribution graph corresponding to the different slant range error.

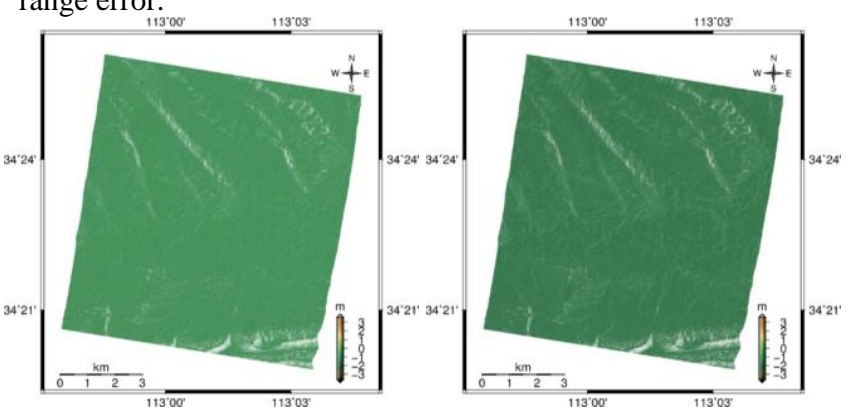

(a) $\Delta r=1 \mathrm{~m}^{11300}$

(b) $\Delta r=2 \mathrm{~m}$

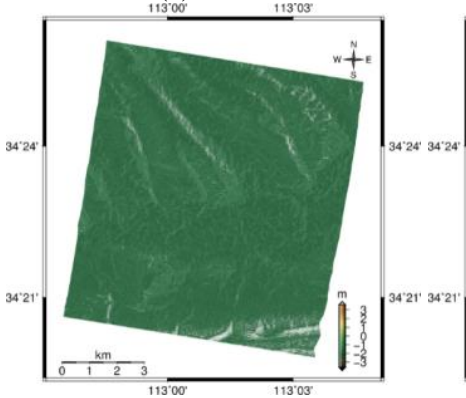

(c) $\Delta \mathrm{r}=2.5 \mathrm{~m}$

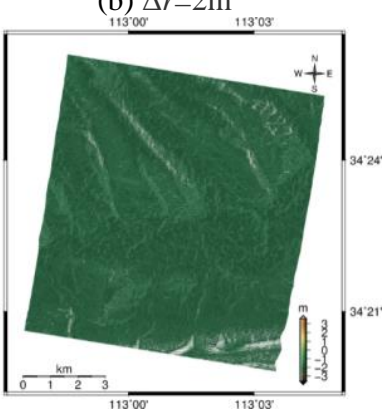

(d) $\Delta r=3 m$

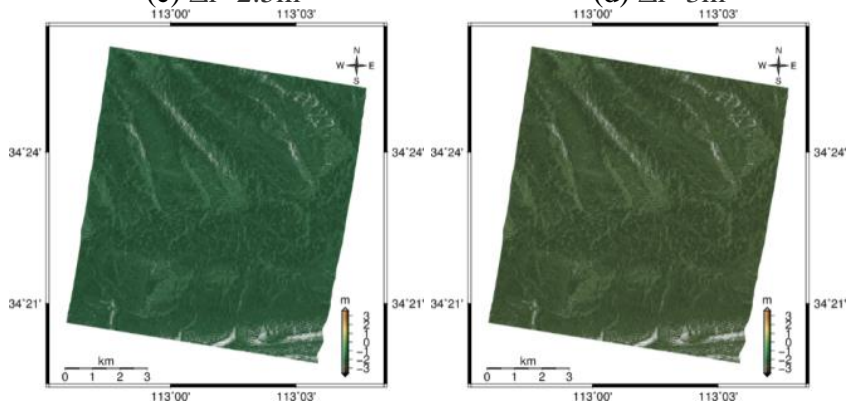

(e) $\Delta r=3.5 \mathrm{~m}$

(f) $\Delta \mathrm{r}=4 \mathrm{~m}$

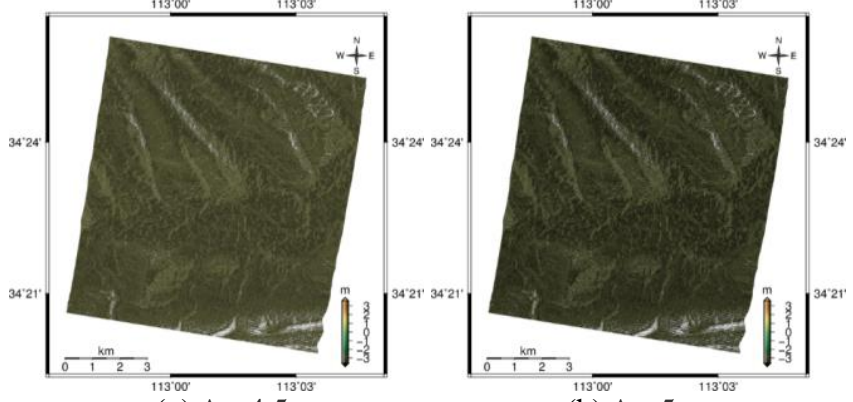

(g) $\Delta r=4.5 \mathrm{~m}$

(h) $\Delta r=5 \mathrm{~m}$

Figure 8. Height error distribution graph induced by different slant range error

The simulation results indicate that the slant range error has obvious influence on the InSAR height measurement. With the increase of slant range error, the height measurement error raises gradually, which show good agreement with the theoretical derivation.

The spatial error distribution graph characterised the pixel-topixel influence of slant range error to height measurement. 
Furthermore, the comprehensive influence of the slant range to height measurement was assessed. The root mean square error (RMSE) was selected as the quantitative indicator. Table 2 represents the statistic results of the height error induced by different slant range error.

\begin{tabular}{cccccc}
\hline Slant Range Error/m & 0 & 1 & 2 & 2.5 & 3 \\
\hline Height RMSE/m & 0.12 & 0.58 & 1.28 & 1.62 & 1.97 \\
\hline Slant Range Error/m & 3.5 & 4 & 4.5 & 5 \\
\hline Height RMSE/m & 2.32 & 2.66 & 3.01 & 3.35 \\
\hline Table 2. Statistic results of the height error induced by slant \\
range error
\end{tabular}

Figure 9 shows the relationship between the height RMSE and slant range error.

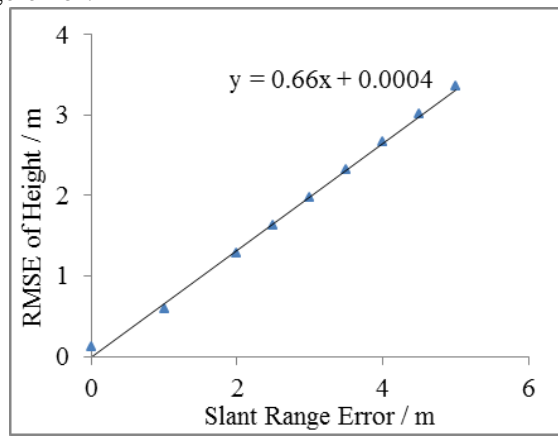

Figure 9. Relationship between the height RMSE and slant range error

The results show that the error propagation coefficient of the slant range error to height measurement is approximate 0.66 , which characterise obvious influence of slant range error to height measurement. The simulation results represent similar trend with the theoretical analysis, which further verify the reliability of the InSAR height measurement error model. Nevertheless, there is certain difference between the simulation results and theoretical analysis. The following three aspects may induce this difference. Firstly, partial approximation and assumption of the theoretical model may result in the deviation. For the theoretical derivation of slant range error model, the first-order derivative model was employed in this research. Actually, the high-order derivative model may be more accurate for the theoretical derivation. Secondly, for the simulation data several processing steps are required to generate the final DEM, especially for resampling, phase unwrapping and geocoding, which may introduce deviation to the InSAR-derived DEM. Finally, only the center point of the image was utilized for the theoretical-based evaluation. While for the simulation validation the whole image was employed to assess the slant range error model. Therefore, the results show certain deviation between the theoretical derivation and simulation validation.

\section{CONCLUSIONS}

The theoretical derivation and simulation validation of the slant range error to InSAR height measurement were implemented in this research. According to the theoretical-based point scale evaluation and spatial simulation validation, the slant range error shows obvious influence on the InSAR height measurement. Therefore, it is essential to determine the accurate and reliable slant range for SAR system.

For the future research, the evaluation and validation for slant range error model may be implemented on the basis of real SAR data. In addition, the application of high-order derivative model for theoretical derivation may be promising in further research.

\section{ACKNOWLEDGEMENTS}

This research was supported by the National Key R\&D Programme of China (No. 2017YFB0502700), Civilian Space Programme of China (No. D010102), National Basic Surveying and Mapping Science and Technology Plan (No. 2018KJ0204/2018KJ0304).

\section{REFERENCES}

Farr, T. G., Hensley, S., Rodriguez, E., Martin, J., and Kobrick, M. 1999. The Shuttle Radar Topography Mission. Proc. CEOS SAR Workshop, ESA-CNES, Toulouse, France, pp. 1-3.

Hanssen, R. F. 2001. Radar Interferometry: Data Interpretation and Error Analysis. Dordrecht, The Netherlands: Kluwer.

Krieger, G., Moreira, A., Fiedler, H. and et al. 2007. TanDEM$\mathrm{X}$ : a satellite formation for high-resolution SAR interferometry. IEEE Transactions on Geoscience and Remote Sensing, 45(11), pp. 3317-3340.

Massonnet, D. 1997. Satellite radar interferometry. American Scientist, 276, pp. 32-39.

Mohr, J. J., Reeh, N., and Madsen, S. N. 1998. Threedimensional glacial flow and surface elevation measured with radar interferometry. Nature, 291, pp. 273-276.

Meyer F., Bamler R., Jakowski N., Fritz T. 2006. The Potential of Low-Frequency SAR Systems for Mapping Ionospheric TEC Distributions. IEEE Geoscience and Remote Sensing Letters, 3(4):560-564

Pitz, W. and Miller, D. 2010. The TerraSAR-X Satellite. IEEE Transactions on Geoscience and Remote Sensing, 48(2), pp. 615-622.

Rosen, P. A., Hensley, S., Joughin, I. R., Li, F. K., Madsen, S. N., Rodriguez, E., and Goldstein, R. 2000. Proc. IEEE Synthetic aperture radar interferometry, 88(3), pp. 333-382.

Rabus, B., Eineder, M., Roth, A., and Bamler, R. 2003. The Shuttle Radar Topography Mission-A new class of digital elevation models acquired by spaceborne radar. ISPRS Journal of Photogrammetry and Remote Sensing, 57(4), pp. 241-262.

Werner, M. 2001. Shuttle Radar Topography Mission (SRTM): Mission overview. Journal of RF-Engineering and Telecommunications (Frequenz), 55(3/4), pp. 75-79.

Werninghausm R. and Buckreuss, S. 2010. The TerraSAR-X mission and system design. IEEE Transactions on Geoscience and Remote Sensing, 48(2), pp. 606-614.

Zebker, H. A. and Goldstein, R. M. 1986. Topographic mapping from interferometric synthetic aperture radar observations. Journal of Geophysical Research, 91(5), pp. 4993-4999.

Zebker, H. A., Rosen, P. A., Goldstein, R. M., Gabriel, A., and Werner, C. L. 1994. On the derivation of coseismic displacement fields using differential radar interferometry: The Landers earthquake. Journal of Geophysical Research, 99(10), pp. 19617-19634. 
The International Archives of the Photogrammetry, Remote Sensing and Spatial Information Sciences, Volume XLII-3, 2018 ISPRS TC III Mid-term Symposium "Developments, Technologies and Applications in Remote Sensing", 7-10 May, Beijing, China

Zink, M., Fiedler, H., Hajnsek, I., Krieger, G., Moreira, A., and Werner, M. 2006. The TanDEM-X mission concept. IEEE
International Geoscience and Remote Sensing Symposium (IGARSS'06), pp. 1938-1941. 